\section{Water Content of a Pine-bark Growing Substrate in a Drying Mineral Soil}

\author{
Anne-Marie Hanson, ${ }^{1}$ J. Roger Harris, ${ }^{2}$ Robert Wright, ${ }^{3}$ and \\ Alex Niemiera ${ }^{4}$ \\ Department of Horticulture, Virginia Polytechnic Institute and State University, \\ 301 Saunders Hall, Blacksburg, VA 24061
}

\section{Naraine Persaud ${ }^{3}$}

Department of Crop and Soil Environmental Sciences, Virginia Polytechnic Institute and State University, 330 Smyth Hall, Blacksburg, VA 24061

Additional index words. plant-available water, container media, transplant, irrigation

Abstract. Newly transplanted container-grown landscape plants are reported to require very frequent irrigation. However, container nurseries in the U.S. commonly use growing substrates that are mostly bark, even though the contribution of bark-based growing substrates to water relations of transplanted root balls is unknown. Therefore, a field experiment was undertaken to determine water relations of a pine-bark substrate (container removed) within a drying mineral soil over a three week period. A range of common production container sizes-3.7 L (\#1), 7.5 L (\#2), 21.9 L (\#7), 50.6 L (\#15), and $104.5 \mathrm{~L}$ (\#25) - was used. The fraction of substrate volume that is water [total volumetric water (TVW)] within the top and middle zones of substrate was compared to TVW at corresponding depths of adjacent mineral soil. The fraction of substrate and soil volume that is plant-available water [plant-available volumetric water (PAVW)] was calculated by subtracting the fraction of substrate or soil volume below where water is unavailable to most plants (measured with pressure plates) [plant-unavailable volumetric water (PUVW)] from each TVW measurement. The pine-bark substrate had a PUVW of 0.32 compared to a PUVW of 0.06 for soil. Top sections of substrate dried to near zero PAVW 6 days after irrigation for all containers. Larger container sizes maintained higher PAVW in middle sections than smaller container sizes, and PAVW was always higher in the adjacent soil than in the embedded substrate. Overall, very little PAVW is held by the embedded pinebark growing substrate, suggesting the need for container substrates with greater water retention once transplanted to mineral soils.

Because it can be produced in a variety of particle sizes, allowing mixtures of desirable air-filled porosity to be created (Fonteno, 1996; Handreck and Black, 1999), composted or aged bark is considered by many to be the best substrate for production of container-grown landscape plants. Pine bark, peat, and sand are the predominant substrate components used for container-grown landscape plants throughout the Southern United States (Yeager et al., 1997). In the Northern United States, hardwood bark predominates, whereas douglas-fir and redwood bark are most common in the western U.S. (Fonteno, 1996). A favorable air-filled porosity during production often results in suboptimal water holding capacity when the container is removed at transplanting (Nelms and Spomer, 1983; Spomer, 1979). Unless drainage is impeded, more frequent irrigation may be needed after transplanting because of increased drainage into the surrounding soil after elimination of the container-induced perched water table (Costello and Paul, 1975) and radial movement of water from the root

Received for publication 8 Jan. 2003. Accepted for publication 27 Aug. 2003.

${ }^{1}$ Graduate assistant.

${ }^{2}$ Associate professor, to whom reprint requests should

be addressed; e-mail rharris@vt.edu.

${ }^{3}$ Professor.

${ }^{4}$ Associate professor.

HortSCiEnCE Vol. 39(3) June 2004
This experiment was undertaken to examine plant-water availability patterns within a pine-
Anisko et al., 1994, da Silva, 1998). bark substrate imbedded within a mineral soil. Our objective was to determine the fundamental relationship between water content of substrate and soil during a drying event, so plants were not included.

\section{Materials and Methods}

A field bed consisting of Groseclose silt loam soil (clayey, mixed, mesic Typic Hapludults; $\mathrm{pH}=6.2$; bulk density $=1.1 \mathrm{~g} \cdot \mathrm{cm}^{-3}$ ) was tilled to 20-cm depth in mid-August 2001, at the Urban Horticulture Center, near the campus of Virginia Tech, Blacksburg, Va. (USDA plant hardiness zone 6a). Fifty holes were spaced $1.2 \mathrm{~m}$ on center, dug to a particular container size, and filled with a mixture (volumetric 2:1) of $100 \%$ pine bark and Scott's Perennial Mix (65\% to $75 \%$ pine bark, $20 \%$ to $25 \%$ sphagnum peat, and $9 \%$ to $15 \%$ perlite; The Scott's Co., Lawrenceville, Va.). This resulted in a substrate that was approximately (by volume) $85 \%$ pine bark, $10 \%$ sphagnum peat, and $5 \%$ perlite. Substrate physical properties, determined as described by Niemiera et al. (1994), were: air space $=21.5 \%$; total porosity $=87.3 \%$; container (water-holding) capacity $=65.8 \%$; bulk density $=0.32 \mathrm{~g} \cdot \mathrm{cm}^{-3}$. Five container sizes were used as templates for hole sizes: 3.7 L (\#1), 7.5 L (\#2), 21.9 L (\#7), 50.6 L (\#15), and 104.5 L (\#25). Ten replications of each size were arranged in a completely randomized design.

TVW was measured with a theta meter $(\theta-$ Probe, Type HH1; Dynamax, Inc., Houston, Texas). The $\theta$-Probe uses TDR technology (Anisko et al., 1994; Rundel and Jarrell, 1991) by using microwave signals to measure the average TVW in the substrate surrounding the length $(6 \mathrm{~cm})$ of the wave guides. Access to center sections of substrate and to the corresponding depth in adjacent soil was through a hole that was held intact by polyvinyl chloride (PVC) pipe sections. A hole was made into the center of each replication, and another was inserted into the surrounding soil, $\approx 20 \mathrm{~cm}$ from the edge of the substrate (Fig. 1). All substrate within the pipes was removed so that hollow access tubes remained. The top of each pipe extended three $\mathrm{cm}$ above the surface of the substrate to allow for covering with aluminum foil. Surface (top sections) measurements of TVW with the $\theta$-Probe are integrated along the top $6 \mathrm{~cm}$, and below-surface measurements (middle sections) for the \#1,\#2,\#7,\#15, and \#25 container sizes and the surrounding soil are integrated along $\approx 9$ to 15,12 to 18,14 to 20,19 to 25 , and 23 to $29 \mathrm{~cm}$ depths, respectively.

The $\theta$-Probe is factory-calibrated to read TVW for mineral and organic soil, but not pinebark substrate. We calibrated the TVW to the pine-bark substrate by comparing uncalibrated readings (organic soil setting) for TVW of 15 substrate-filled containers in various degrees of drying, with TVW calculated by weighing samples before and after drying to a constant weight at $70^{\circ} \mathrm{C}$. The volume of water contained within each container was calculated by converting grams of water lost by drying to $\mathrm{cm}^{3}$ $\left(1 \mathrm{~g}=1 \mathrm{~cm}^{3}\right)$. Containers (for calibration only) were fashioned from $\mathrm{PVC}$ pipe sections $(5 \mathrm{~cm}$ 


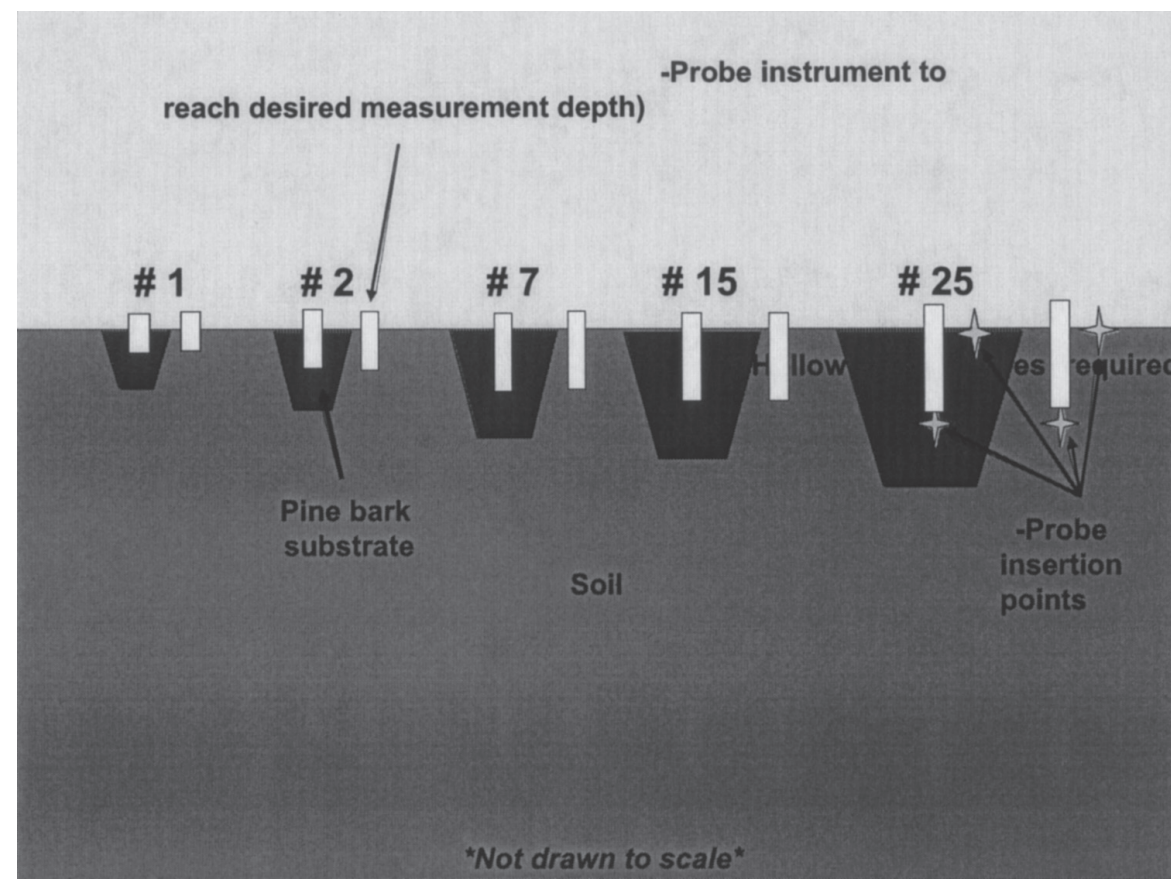

Fig. 1. Diagram of pine-bark substrate installed in holes in mineral soil. Holes were made from templates of various container sizes. Hollow access tubes denote access and stars denote insertion points for $\theta$-Probe measurements. Experimental units were arranged in a completely random statistical design. $\mathrm{n}=10$.

in diameter and $10 \mathrm{~cm}$ long). The bottom of each container was covered with four layers of cheese cloth, held to the container bottom with a rubber band, to contain the substrate. Wave guides of the $\theta$-Probe were inserted into substrate through the top of the containers. Calibration revealed that the actual was related to the measured TVW of the pine-bark substrate by the following equation: actual $=0.0706+$ $1.1102 \times$ measured $\left(R^{2}=0.99\right)$. $\theta$-Probe readings were adjusted accordingly.

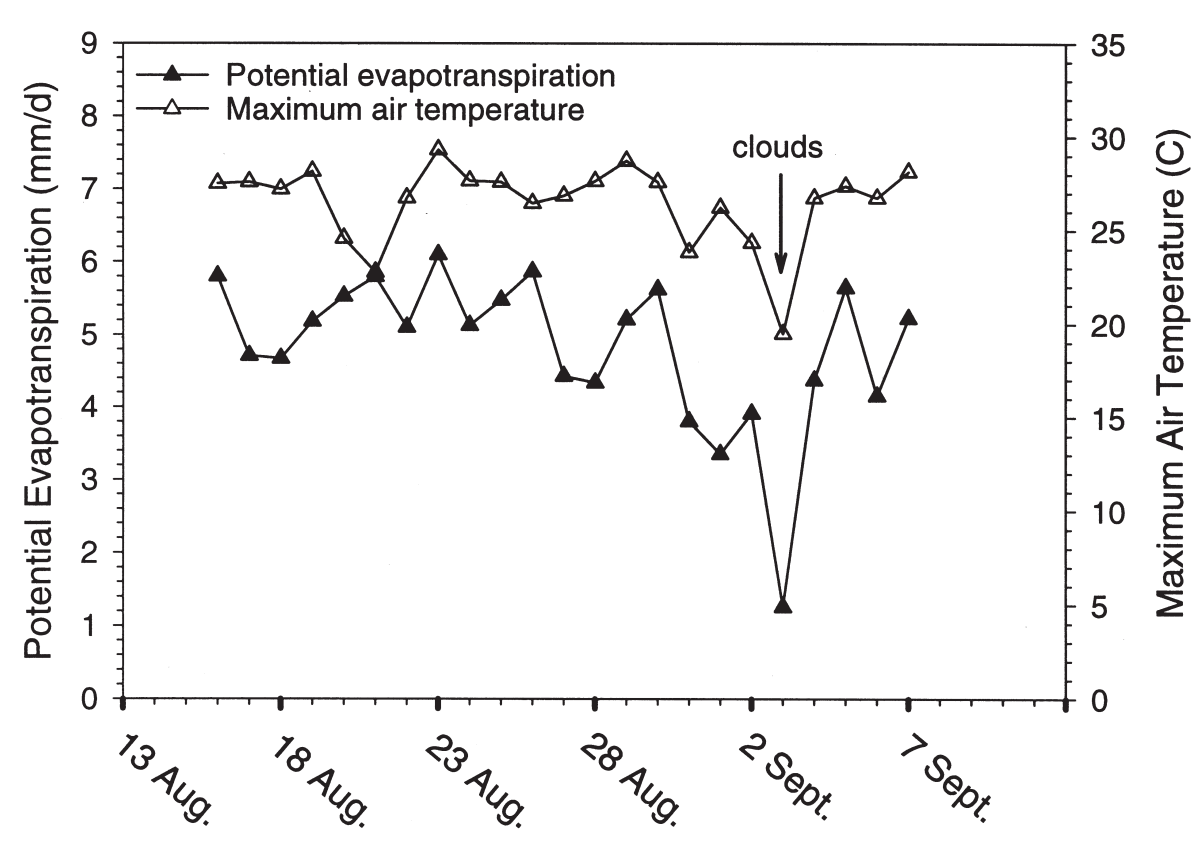

Fig. 2. Potential evapotranspiration (left axis) and maximum daily air temperature (right axis) during experiment.
All replications of embedded substrate were lightly tamped, and $5 \mathrm{~cm}$ water was applied over the experimental field on 16Aug. with overhead sprinklers. $\theta$-Probe measurements were taken $24 \mathrm{~h}$ later. No further irrigation was applied during the experiment. Substrate settled $\approx 2 \mathrm{~cm}$ vertically after tamping and irrigation. An onsite weather station (DYNAMET; Dynamax, Houston, Texas) recorded weather variables, from which potential evapotranspiration (van Bavel, 1966) was calculated (Fig. 2). A 2.6-

\section{은} mean mean TVW throughout the experiment (Figs. as PAVW (Figs. 3B, D, F, and H), substrate at both depths had lower PAVW than adjacent soil for \#2 (Fig. 3B) and \#7 (Fig. 3D) volumes. Middle substrate sections had similar PAVW as top sections of adjacent soil for \#15 (Fig. $3 \mathrm{~F}$ ) and \#25 (Fig. 3H) volumes for most of the experiment. Top sections of substrate PAVW

HortScience Vol. 39(3) June 2004 


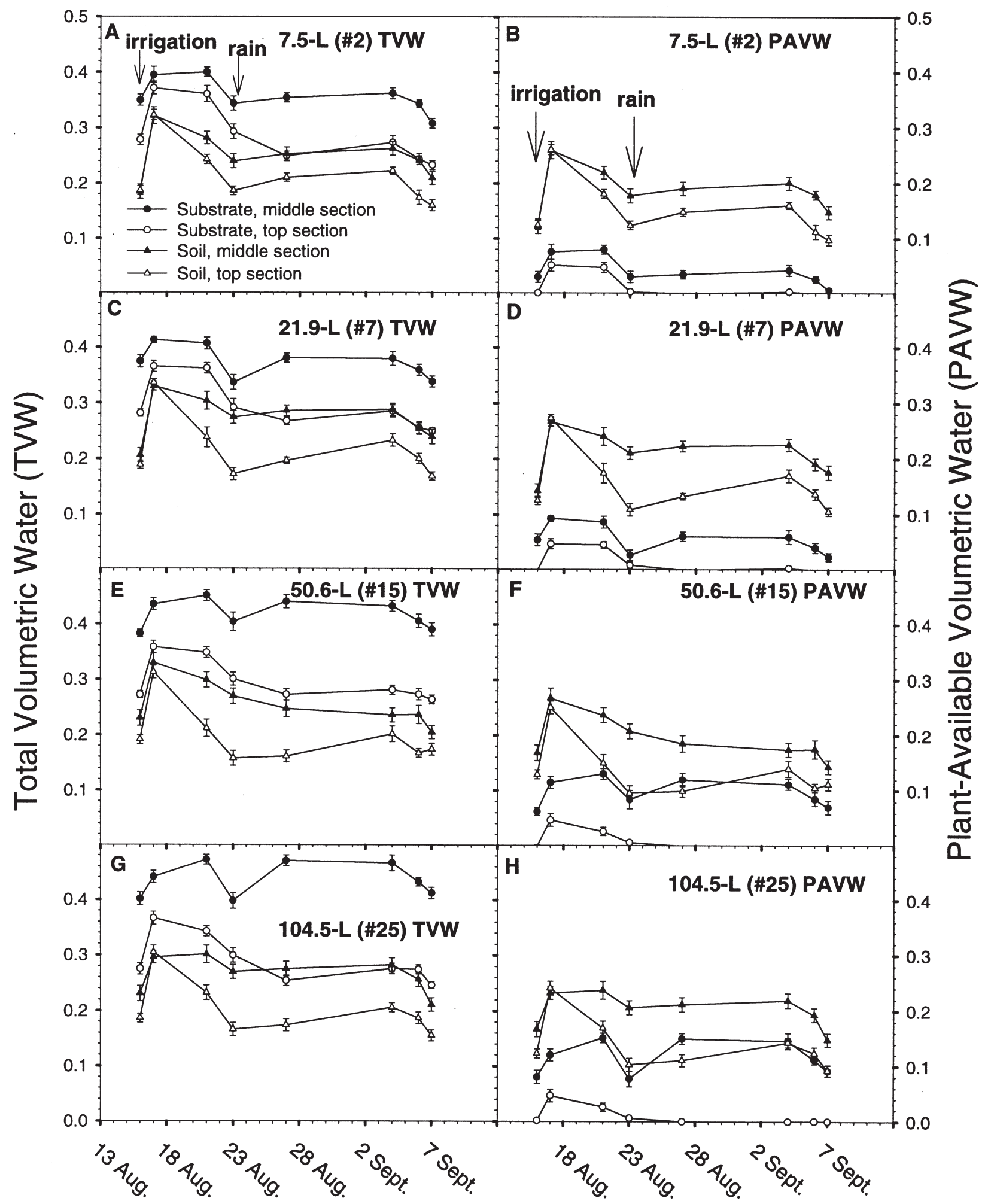

Fig. 3. Fraction of substrate and soil volume that is water (total volumetric water, TVW) at surface and middle of embedded 7.5-L (\#2), 21.9-L (\#7), 50.6-L (\#15), and 104.5-L (\#25) pine-bark substrate and at corresponding depths of adjacent soil ( $\mathbf{A}, \mathbf{C}, \mathbf{E}, \mathbf{G})$ and fraction of substrate and soil volume that is plant-available water (plant-available volumetric water, PAVW) at the same locations (B, D, F, H). Data for 3.7-L (\#1) substrate are not shown. Bars represent sE mean. $\mathrm{n}=10$.

were never $>0$ after 23 Aug., even after the 2.6-cm rain. Lack of response to the rain may be partly due to a hydrophobic condition that has been reported to develop when TVW drops below 0.35 in pine-bark substrate (Airhart et al., 1978). The same trend for top-of-the-substrate measurements for \#2, \#5,\#15, and \#25 sizes is evident. Low plant-available water for the top sections of embedded substrate was likely due to evaporation, so it is not surprising that trends were similar for the different sizes. Evaporation in actual landscape situations may be slowed by mulch (Smith and Rakow, 1992). In addition, lateral movement of water in soil may have occurred after the rainfall of the night of 23 Aug., since top sections of soil adjacent to all substrate-filled holes increased (Fig. 3).

Substrate and soil TVW at similar measurement depths showed the same general drying and rewetting patterns for \#2 and \#7 sizes (Fig. 3A and C), suggesting that little water moved laterally between the coarse substrate and finer textured soil (Hillel, 1982). The middle-of-substrate measurements for \#15 and 
\#25 sizes (Fig. 3E and G) show a somewhat increased TVW compared to adjacent soil after the 23 August rain, probably due to increased infiltration depth for these sizes. PAVW in the middle sections of substrate for all volumes were recharged from the $23 \mathrm{Aug}$. rain (Fig. $3 \mathrm{~B}, 3 \mathrm{D}, 3 \mathrm{~F}$, and $3 \mathrm{H}$ ), and PAVW increased with container size.

PAVW within all embedded substrate was consistently below PAVW in surrounding field soil at corresponding depths (Fig. 3B, D, F, and $\mathrm{H}$ ). Although soil has a more favorable PAVW than modern bark substrate, the airfilled porosity of soil during production in containers is generally unfavorable, especially in periods of frequent rainfall and slow plant growth (Handreck and Black, 1999). Container substrates that work well in production, such as the pine-bark substrate in our experiment, become drier when embedded in well drained soil. For example, a peat:sand mixture was reported to lose $53 \%$ of total water held at container capacity when embedding into soil with the container removed, and the embedded substrate had a lower water content than the surrounding soil after irrigation (Nelms and Spomer, 1983). Costello and Paul (1975) found that root balls of transplanted sweet gum (Liquidambar styraciflua L.) trees (grown in sand-peat-sawdust mix) were drier than the surrounding soil and contained root balls. Substrates that work well for container production but retain more plant-available water after transplanting are needed.

A high plant-unavailable water fraction in pine bark has been demonstrated by others (Beardsell et al., 1979; da Silva et al., 1998). da Silva et al. (1998) explained that much of the water in pine-bark substrates are tightly bound to organic compounds, mineral crystals, or embedded in occluded pores. Our data indicate that once embedded, the pine-bark substrate retains very little plant-available water in the top $6 \mathrm{~cm}$ and middle sections ( 9 to 15,12 to 18,14 to 20,19 to 25 , and 23 to $29 \mathrm{~cm}$ depths for \#1, \#2, \#7, \#15, and \#25 container sizes, respectively), even immediately after irrigation, and that embedded substrate from larger containers retains more water during a dry-down period than substrate from smaller containers. Transpiring plants will reduce the already low available water very quickly until roots grow into the backfill-soil. Actual water withdrawal rate will vary according to species, size and growth rate (Witmer, 2000). Rapid root growth beyond the original container root ball is therefore critical, especially if irrigation or rainfall is negligible. Our experiment was conducted in typical summer weather with high evapotranspiration potential (Fig. 1). Rate of drying and magnitudes of differences between substrate and soil will likely differ somewhat as weather changes. For example, the substrate and soil will probably dry more slowly in cooler conditions as is common in spring and fall. However, it is unlikely that basic relationships illustrated by our data, such as relatively low PAVW of the embedded pinebark substrate and increasing PAVW in middle sections as container size increases will differ considerably between seasons.

As noted by Day and Skoupy (1971) for container-grown forest seedlings, retention of water within root balls after transplanting will likely increase post-transplant survival. Water conservation measures such as mulching and use of water-conserving plants (Smith and Rakow, 1992) will also increase transplant success.

\section{Literature Cited}

Airhart, D.L., N.J. Natarella, and F.A. Pokorny. 1978. Influence of initial moisture content on the wettability of a milled pine bark medium. the wettability of a milled

HortScience 13:432-434.
Anisko, T., D.S. NeSmith, and O.M.Lindstrom. 1994. Time-domain reflectometry for measuring water content of organic growing media in containers. HortScience 29:1511-1513.

Beardsell, D.V., D.G. Nichols, and D.L. Jones. 1979. Water relations of nursery potting media. Scientia Hort. 11:9-7.

Brady, N.C. 1990. The nature and properties of soils. p. 146. 10th ed. Macmillan. New York.

Costello, L. and J.L. Paul. 1975. Moisture relations in transplanted container plants. HortScience 10:371-372

da Silva, F.F., R. Wallach, A. Polak, and Y. Chen. 1998. Measuring water content of soil substitutes with time-domain reflectometry. J. Amer. Soc. Hort. Sci. 123:734-737.

Day, R.J. and J. Skoupy. 1971. Moisture storage capacity and postplanting patterns of moisture movement from seedling containers. Can. J. For. Res. 1:151-158.

Fonteno, W.C. 1996. Growing media: Types and Physical/chemical properties, p. 93-122. In: D.W. Reed (ed.). Water, media, and nutrition for greenhouse crops. Ball Publ.. Batavia, Ill.

Handreck, K.A. and N.D. Black. 1999. Growing media for ornamental plants and turf, p. 110-129. 3rd ed. UNSW Press. Sydney, Australia.

Hillel, D. 1982. Introduction to soil physics, p. 107-132. Academic Press, San Diego, Calif.

Klute, A. 1998. Water retention: Laboratory methods, p. 635-640. In: Methods of soil analysis. Part 1. Physical and mineralogical methods. 2nd ed. Amer. Soc. Agron.

Kramer, P.J. and J.S. Boyer. 1995. Water relations of plants and soil, p. 104-105. Academic Press, San Diego, Calif.

Murray, J.D., J.D. Lea-Cox, and D. Ross. 2001. Time domain reflectometry accurately monitors plant water use and reduces leaching volumes in soilless substrates. Proc. SNA Res. Conf. 46:595-599.

Nelms, L.R. and L.A. Spomer. 1983. Water retention of container soils transplanted into ground beds. HortScience 18:863-866.

Rundel, P.W. and W.M. Jarrell. 1991. Water in the environment, p. 29-56. In: R.W. Pearcy, J. Ehleringer, H.A. Mooney, and P.W. Rundel (eds.). Plant physiological ecology: Field methods and instrumentation. Chapman and Hall, New York.

Smith, A.M. and D.A. Rakow. 1992. Strategies for reducing water input in woody landscape plantings. J. Arboricult. 18:165-170.

Spomer, L.A. 1979. Three simple demonstrations of physical effects of soil amendments. HortScience 14:75-77.

van Bavel, C.H.M. 1966. Potential evaporation: The combination concept and its experimental verification. Water Resour. Res. 2:455-467.

Witmer, R.K. 2000. Water use of landscape trees during production and during establishment in the landscape. PhD diss. Va. Polytech. Inst. State Univ., Blacksburg.

Yeager, T.H., C.H. Gilliam, T.E. Bilderback, D.C. Fare, A.X. Niemiera, and K. Tilt. 1997. Best management practices guide for producing container-grown plants. S. Nurseryman's Assn., Marietta, Ga. 